\title{
Equal Force Recovery in Dysferlin-Deficient and Wild-Type Muscles Following Saponin Exposure
}

\author{
Piming Zhao, Li Xu, Younss Ait-Mou, Pieter P. de Tombe, and Renzhi Han \\ Department of Cell and Molecular Physiology, Stritch School of Medicine, Loyola University Medical Center, Maywood, \\ IL 60153, USA \\ Correspondence should be addressed to Renzhi Han, renhan@lumc.edu
}

Received 28 April 2011; Revised 24 June 2011; Accepted 19 July 2011

Academic Editor: Robert J. Bloch

Copyright () 2011 Piming Zhao et al. This is an open access article distributed under the Creative Commons Attribution License, which permits unrestricted use, distribution, and reproduction in any medium, provided the original work is properly cited.

Dysferlin plays an important role in repairing membrane damage elicited by laser irradiation, and dysferlin deficiency causes muscular dystrophy and associated cardiomyopathy. Proteins such as perforin, complement component C9, and bacteria-derived cytolysins, as well as the natural detergent saponin, can form large pores on the cell membrane via complexation with cholesterol. However, it is not clear whether dysferlin plays a role in repairing membrane damage induced by pore-forming reagents. In this study, we observed that dysferlin-deficient muscles recovered the tetanic force production to the same extent as their WT counterparts following a 5 -min saponin exposure $(50 \mu \mathrm{g} / \mathrm{mL})$. Interestingly, the slow soleus muscles recovered significantly better than the fast extensor digitorum longus (EDL) muscles. Our data suggest that dysferlin is unlikely involved in repairing saponininduced membrane damage and that the slow muscle is more efficient than the fast muscle in repairing such damage.

\section{Introduction}

Mutations in the dysferlin gene lead to the development of several types of muscle wasting diseases including limbgirdle muscular dystrophy type 2B (LGMD2B) [1, 2], Miyoshi myopathy (MM) [2], and a distal anterior compartment myopathy (DACM) [3], together termed dysferlinopathy. Dysferlinopathy has also been shown to develop a lateonset cardiomyopathy $[4,5]$. Dysferlin is a $230 \mathrm{kDa}$ protein containing multiple-tandem C2 domains, and it is widely expressed in different tissues and cells including skeletal and cardiac muscle [6]. Previous work has established a role for dysferlin in muscle membrane repair since the dysferlindeficient skeletal [7] and cardiac [5] muscle cells fail to efficiently reseal the membrane disruptions elicited by laser irradiation. Although the exact action of dysferlin in the membrane repair system of striated muscle remains poorly understood, it has been suggested that dysferlin may play a role in the membrane vesicle fusion step based on its primary structure properties $[8,9]$.

It is not very clear how laser irradiation induces membrane damage, but there is evidence showing that peroxidation of the plasma membrane lipids may be involved in the photo-induced cell lysis $[10,11]$. Such membrane damage may be similar to mechanical membrane tears as both require dysferlin and MG53 for repair at least in muscle cells $[5,7,12]$. Interestingly, in addition to oxidationinduced membrane damage, various pore-forming reagents can also cause a loss of membrane integrity and cell death in vivo. For example, perforin is released upon degranulation of cytotoxic T cells (CTLs) and forms transmembrane pores that promote translocation of granzymes into the cytoplasm of pathogen-infected cells, leading to their apoptotic death [13]. Previous studies have shown that cytotoxic $\mathrm{T}$ cells contribute to muscle pathology in dystrophin-deficient muscular dystrophy through perforin-dependent as well as perforin-independent mechanisms [14]. Cytotoxic T cells were also found in other inflammatory myopathies where they secreted perforin and invaded muscle fibers [15]. In addition, the 5th to 9th components (C5 to C9) of the complement system is involved in terminal activation of complement that leads to the formation of a large membrane lytic pore complex-the membrane attack complex (MAC) on the target cell membrane [16-18]. Interestingly, the membrane inserting part of both perforin and C9 is 
mediated by the MACPF domain [19] which surprisingly shares structural similarity to the bacterial cholesteroldependent cytolysins (CDCs) $[20,21]$. Our recent study has shown that the complement activation contributes to muscle pathology in dysferlinopathy [22]. Moreover, the betaamyloid can also form ring-shaped structures reminiscent of bacterial pore-forming toxins (PFTs) [23], which have membrane-perforating activity [24]. Interestingly, increased sarcolemmal and interstitial amyloid deposits were observed in dysferlinopathy patient muscles, and mutant dysferlin was found to be present in the amyloid deposits [25]. All the above-mentioned pore-forming proteins (PFPs) induce pore formation with diameters up to $50 \mathrm{~nm}$ through a very similar cholesterol-dependent mechanism [26]. Such a mechanism, through complexation with cholesterol, also applies to saponins which are natural detergents found in many plants $[27,28]$.

Despite the devastating consequences of membrane perforation, mammalian cells can recover the plasma membrane integrity depending on the severity and duration of the membrane damage. For example, it has been shown that striated myocytes can recover within seconds following membrane damage induced by laser irradiation and microelectrode penetration in the presence of $\mathrm{Ca}^{2+}$, dysferlin, and MG53 $[5,7,12]$. In addition, cells can restore plasma membrane integrity at the minute time scale $(<1 \mathrm{~h})$ following the formation of pores $(30-50 \mathrm{~nm}$ in diameter) by CDCs or perforin $[13,29,30]$. Removal of the pores from the cell surface by calcium-dependent endocytosis and/or shedding of vesicles appears to be a critical step to repair membrane damage induced by PFPs [13, 30-32]. However, it remains unclear whether dysferlin is involved in repairing membrane damage induced by PFPs. In the present study, we designed experiments to address this question and provided evidence to show that dysferlin appears to be dispensable for membrane repair following saponin-induced membrane damage.

\section{Materials and Methods}

2.1. Mice. All animal studies were reviewed and approved by the Institutional Animal Care and Use Committee of Loyola University Chicago (LU no. 202288 and LU no. 202769). The wild-type C57BL/6J (stock number: 000664), $\mathrm{A} / \mathrm{J}$ (stock number: 000646), and $\mathrm{C} 57 \mathrm{BL} / 6 \mathrm{~J}-\mathrm{Chr}^{\mathrm{A} / \mathrm{J}} / \mathrm{NaJ}$ (stock number: 004384) mice were obtained from the Jackson Laboratory. Mice were maintained at Loyola University Medical Center Animal Facility in accordance with animal usage guidelines. The $\mathrm{A} / \mathrm{J}$ and $\mathrm{C} 57 \mathrm{BL} / 6 \mathrm{~J}-\mathrm{Chr} 6^{\mathrm{A} / \mathrm{J}} / \mathrm{NaJ}$ were genotyped by tail PCR using the following primers: WT-F, 5'-CAAACCATTCCCAGTCCTCCT-3'; AJ-R, 5' AAGAGAAGGCAACAGGTGACA-3'; AJ-F, 5' -CAGAGTTCCAACGCCCTACT- $3^{\prime}$. The WT allele will produce a 449bp band, and the mutant allele will produce a $1-\mathrm{kb}$ band. The $20 \mu \mathrm{L}$ PCR reaction contained 4 pmol WT-F, 4 pmol AJ-F, 8 pmol AJ-R primers, and $50 \mathrm{ng}$ of DNA extracted from mice tails. PCR amplification was conducted for 40 cycles under standard conditions (denaturation at $95^{\circ} \mathrm{C}$ for 30 seconds, annealing at $58^{\circ} \mathrm{C}$ for 30 seconds, and elongation at $72^{\circ} \mathrm{C}$ for
1 minute). The male and female mice at 12 to 24 weeks of age were used unless otherwise specified in the text.

2.2. Antibodies. The mouse monoclonal anti-dysferlin antibody Hamlet (Novocastra) was used for the western blotting and immunofluorescence analyses. A monoclonal antibody against caveolin-3 (Transduction Laboratories) and an antilaminin $\alpha 2$-chain antibody (Alexis Biochemicals) were used for immunofluorescence analysis. DAPI was used to stain the nuclei. Peroxidase-conjugated secondary antibodies were obtained from Roche. Alexa Fluor 488- or 555-conjugated secondary antibodies were obtained from Invitrogen.

2.3. Serum Creatine Kinase Analysis. Serum samples from mice were obtained by tail bleeding, using a Sarstedt microvette $\mathrm{CB} 300$, from nonanesthetized restrained mice according to institutional guidelines. Red cells were pelleted by centrifugation at 10,000 rpm for 4 minutes, and serum was separated, collected, and analyzed immediately without freezing. Serum creatine kinase assays were performed with an enzyme-coupled assay reagent kit (Stanbio Laboratory) according to the manufacturer's instructions. Absorbance at $340 \mathrm{~nm}$ was measured every $30 \mathrm{sec}$ for $2 \mathrm{~min}$ at $37^{\circ} \mathrm{C}$ so that changes in enzyme activity could be calculated.

2.4. Western Blotting. Muscle protein samples were separated by SDS-PAGE and transferred onto PVDF membranes. Membranes were blocked with 5\% nonfat dry milk in TBST buffer (Tris- $\mathrm{HCl} 50 \mathrm{mM}, \mathrm{NaCl} 150 \mathrm{mM}, \mathrm{pH}$ 7.4, Tween$200.1 \%$ ) and incubated with primary antibodies overnight at $4^{\circ} \mathrm{C}$. Blots were washed three times with TBS-T for 10 minutes each and incubated with Alexa Fluor 488- or 555conjugated secondary antibodies ( $1: 500$ dilution in TBS-T; Invitrogen) for 1 hour at room temperature. After washing $3 \times 10$ minutes with TBS-T buffer, the membranes were directly imaged for fluorescence using the Typhoon Trio plus imager (GE Healthcare Life Sciences, Inc.).

2.5. HઐE Staining, Immunofluorescence Analysis, and Central Nucleated Fiber Counting. Histopathology studies were performed as described previously $[33,34]$. Several hematoxylin and eosin stained sections $(7 \mu \mathrm{m})$ at the belly of the quadriceps, iliopsoas, EDL, and soleus muscles were prepared to characterize skeletal muscle pathology. Immunofluorescence staining was performed as described previously [33, 34]. Anti-dysferlin antibody Hamlet was used at 1:40 dilution. Anti-caveolin-3 antibody was used at 1:1000 dilution. Antilaminin $\alpha 2$ antibody was used at 1:400 dilution. All the secondary antibodies were used at 1:400 dilution. The numbers of central nucleated muscle fibers and the total muscle fibers were counted on muscle sections costained with caveolin- 3 and DAPI or laminin $\alpha 2$ and DAPI using Image Pro Plus 6.

2.6. Contractile Force Measurement. Contractile force was measured in vitro on extensor digitorum longus (EDL) and soleus muscles from C57BL/6J and dysferlin-deficient mice as described previously [35]. Mice were anesthetized by 
an intraperitoneal (I.P.) injection of a mixture of ketamine $(87.5 \mathrm{mg} / \mathrm{kg})$ and xylazine $(12.5 \mathrm{mg} / \mathrm{kg})$. Intact muscles were removed from each mouse after the mice were euthanized by cervical dislocation after deep anesthesia. Muscles were immersed in an oxygenated bath $\left(95 \% \mathrm{O}_{2}, 5 \% \mathrm{CO}_{2}\right)$ that contained Tyrode solution ( $\mathrm{pH}$ 7.4) at room temperature. For each muscle, one tendon was tied securely with a 6-0 suture (Surgical Specialties Corporation) to a force transducer/servo motor (Aurora Scientific Inc., Model: 300C-LR), and the other tendon to a fixed pin. Using twitches with pulse duration of $0.2 \mathrm{~ms}$, the voltage of stimulation was increased to achieve a maximum twitch. Twitches were then used to adjust the muscle length to the optimum length for force development $\left(L_{0}\right)$. The muscle length was set at $L_{0}$, and muscles were stimulated for $300 \mathrm{~ms}$. Stimulation frequency was increased until the force reached a plateau at maximum isometric tetanic force $\left(P_{0}\right)$.

2.7. Saponin Treatment. After three consecutive tetanic contractions with 3 minutes intervals in between, the muscle was incubated with saponin (Sigma) at $50 \mu \mathrm{g} / \mathrm{mL}$ in Tyrode solution for 5 minutes. To assess the force recovery following saponin-induced membrane injury, tetanic contractions were recorded starting at 10 minutes following saponin washout, once every 10 minutes for one hour in total. The data were digitized, collected, and analyzed using the ASI Dynamic Muscle Control software (DMC V5.294).

2.8. Statistical Analysis. Data were presented as mean \pm SEM, and statistical significance $(P<0.05)$ was determined by the Student's $t$-test for two groups or two-way ANOVA for multiple groups using Prism 5.02 (GraphPad). When the overall $F$-ratio for the ANOVA was significant, the differences between individual group means were determined by a single Student's $t$-test.

\section{Results}

3.1. Characterization of C57BL/6J-Chr6 ${ }^{A / J}$ Mice. In this study, we employed a new dysferlin-deficient mouse strain (C57BL/6J-Chr6 $\left.{ }^{\mathrm{A} / \mathrm{J}} / \mathrm{NaJ}\right)$ from Jackson Laboratory. This strain is an inbred C57BL/6J strain with its chromosome 6 replaced with another inbred A/J strain, originally developed by Nadeau et al. from the Case Western Reserve University [36]. Since the mouse dysferlin gene is located on the chromosome 6 , the $\mathrm{C} 57 \mathrm{BL} / 6 \mathrm{~J}-\mathrm{Chr} 6^{\mathrm{A} / \mathrm{J}} / \mathrm{NaJ}$ mice carry the retrotransposon insertion in the dysferlin gene that is present in the parental A/J strain [37]. This strain is very similar to the B6.A/J-Dys ${ }^{\text {prmd }}$ strain used by Lostal et al. [38] except that the entire chromosome 6 in our strain is from $\mathrm{A} / \mathrm{J}$ mice while the B6.A/J-Dysf $\mathrm{f}^{\text {prmd }}$ strain was derived by backcrossing the $\mathrm{A} / \mathrm{J}$ mice with $\mathrm{C} 57 \mathrm{BL} / 6 \mathrm{~J}$ mice for 4 generations. The C57BL/6J-Chr6 ${ }^{\mathrm{A} / \mathrm{J}} / \mathrm{NaJ}$ mice were genotyped by a PCR method of the tail snips as described in Section 2. A single band of $449 \mathrm{bp}$ and $\sim 1.0 \mathrm{~kb}$ were produced in the WT and the homozygous mutant samples, respectively, while the heterozygous mice yielded two major bands ( $449 \mathrm{bp}$ and $1.0 \mathrm{~kb}$ ) with additional faint nonspecific bands (Figure 1(a)).
Both western blotting and immunofluorescence staining analyses confirmed that the dysferlin protein is completely absent in the skeletal muscle of the homozygous mutant mice (Figures 1(b) and 1(c)). H\&E staining showed that the mice developed dystrophic features (Figure 2(a)) similar to other dysferlin-deficient mice $[7,37,38]$, but the dystrophic phenotype progressed earlier and faster than the parental A/J strain. We observed that the quadriceps muscles had sparsely distributed necrotic muscle fibers and centrally nucleated muscle fibers starting from 2 months of age and that the numbers of such muscle fibers progressively increased. The quadriceps muscle from the male $\mathrm{C} 57 \mathrm{BL} / 6 \mathrm{~J}-\mathrm{Chr}^{\mathrm{A} / \mathrm{J}}$ mice at 4 months of age showed a slightly increased percentage of central nucleated muscle fibers compared to age- and sexmatched $\mathrm{A} / \mathrm{J}$ mice $(7.3 \pm 0.9 \%$ versus $4.5 \pm 0.3 \% ; N=$ 14 and 16; resp., $P=0.009)$. Compared to the quadriceps muscle, the iliopsoas muscle from either $\mathrm{A} / \mathrm{J}$ or $\mathrm{C} 57 \mathrm{BL} / 6 \mathrm{~J}-$ Chr6A/J mice had more central nucleated muscle fibers (11.9 $\pm 3.2 \%$ and $27.4 \pm 4.8 \%$, resp.) (Figures $2(\mathrm{a})$ and $2(\mathrm{~b})$ ). The serum creatine kinase level in the C57BL/6J-Chr6 ${ }^{\mathrm{A} / \mathrm{J}}$ mice at 4 months of age was significantly elevated compared to that in the WT controls $(157 \pm 42$ versus $541 \pm 65 \mathrm{IU} / \mathrm{L} ; N=6$ and 10 for WT and mutant; resp., $P<0.001$ ) (Figure 2(c)). Thus, the C57BL/6J-Chr6 $6^{\mathrm{A} / \mathrm{J}} / \mathrm{NaJ}$ strain is a true dysferlin mutant mouse model in the C57BL/6J background (except the chromosome 6) and was used in the following studies (referred to as "dysferlin-deficient").

3.2. Muscle Force Recovery Following Saponin Exposure. Saponins are a diverse class of natural detergents found in many plants. Through complexation with cholesterol, saponin perforates the cell membrane. We used saponin to induce membrane pore formation in WT or dysferlin-deficient extensor digitorum longus (EDL) and soleus muscles and examined force recovery following saponin treatment. Both dysferlin-deficient EDL and soleus muscles displayed a limited overt pathology with a few centrally nucleated fibers (Figure 3), which allowed us to study the consequence of dysferlin deficiency on force recovery following saponin exposure without much preexisting dystrophic alterations. We performed preliminary experiments to test several doses of saponin (from 10 to $500 \mu \mathrm{g} / \mathrm{mL}$ ) and treated the WT EDL muscle for either $1 \mathrm{~min}$ or $5 \mathrm{~min}$ at room temperature (RT). We then selected $50 \mu \mathrm{g} / \mathrm{mL}$ of saponin for 5 -min incubation, as this treatment resulted in a tetanic force loss of $\sim 85 \%$ in WT EDL muscle at 10 minutes after the treatment (Figures 4(a)-4(d)). We also tested a tetanic contraction at one minute after saponin washout; however, this tetanic contraction greatly decreased the final force recovery (data not shown). This data indicates that, by one minute after saponin exposure, a tetanic contraction stimulus would cause further muscle force loss. Thus, in our standard protocol, we started the tetanic force measurement 10 minutes after saponin washout unless otherwise specified.

Upon application of saponin, the baseline tension gradually increased and reached the maximum level at around 1.5 minutes after that it slowly returned to near the preexposure baseline (Figure 4(b)). The increase in the baseline 


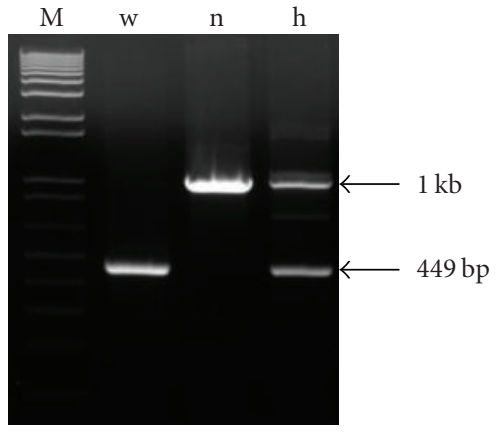

(a)

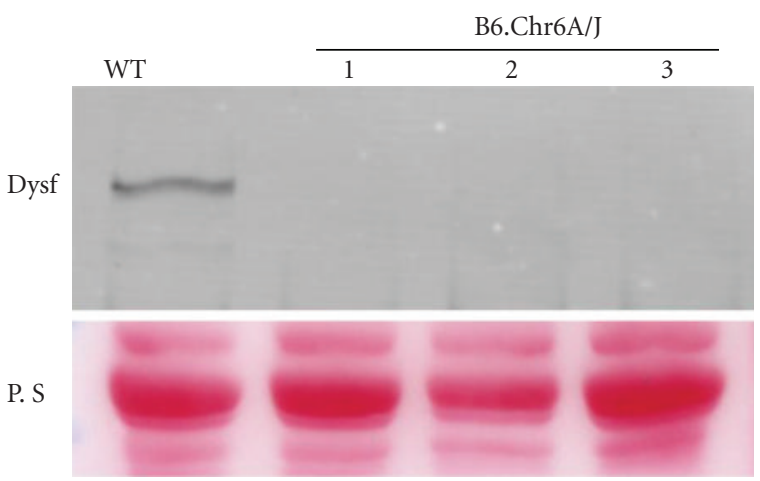

(b)

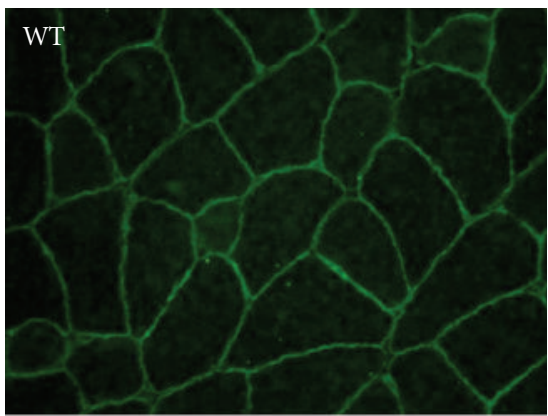

B6.Chr6A/J

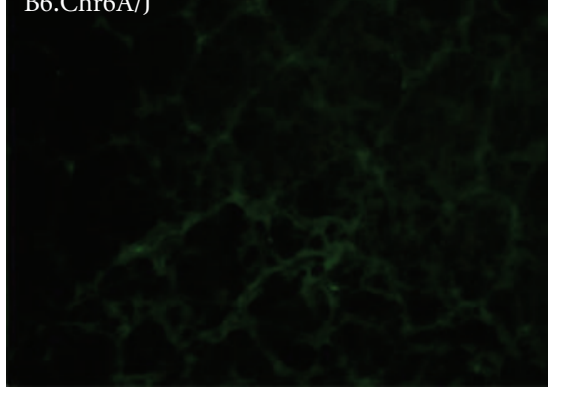

(c)

Figure 1: Disrupted expression of dysferlin in skeletal muscle of C57BL/6J-Chr6 ${ }^{\mathrm{A} / \mathrm{J}} / \mathrm{NaJ}$ mice. (a) PCR genotyping of WT (w), C57BL/6J$\mathrm{Chr6}^{\mathrm{A} / \mathrm{J}} / \mathrm{NaJ}(\mathrm{n})$, and heterozygous (h) mice. (b) Western blotting analysis of the quadriceps muscles from WT and C57BL/6J-Chr6 $6^{\mathrm{A} / \mathrm{J}} / \mathrm{NaJ}$ (B6.Chr6A/J) mice using the monoclonal anti-dysferlin antibody (Dysf). The bottom panel is the same blot stained with Ponceau-S (P.S). (c) Immunofluorescence labeling of muscle sections from WT and dysferlin-deficient mice with anti-dysferlin antibody.

tension indicates $\mathrm{Ca}^{2+} / \mathrm{Na}^{+}$entry through saponin-induced membrane pores, while the subsequent decrease in the muscle tension is most likely due to secondary damage inside the muscle cell after membrane permeabilization. The tetanic force gradually recovered from $15.5 \pm 2.5 \%$ at 10 minutes to $42.1 \pm 4.7 \%$ at 40 minutes of the initial force prior to the treatment and did not significantly increase further after 40 minutes (Table 1 and Figures 4(c)-4(d)). These data suggest that the WT muscle can gradually repair the membrane damage induced by saponin and that this repair process may take up to 30-40 minutes. The force did not recover to $100 \%$, indicating that some irreversible damage occurred within the muscle. Interestingly, the tetanic force also recovered to the same level within the same time frame in the dysferlindeficient EDL muscle following the saponin treatment ( $N=5$ for either WT or mutant) (Figure 4(d) and Table 1$)$.
These data suggest that, unlike the laser-induced membrane damage, saponin-induced membrane damage does not seem to require dysferlin for repair.

Next, we examined the effect of saponin exposure on the tetanic force recovery in the soleus muscle, which are composed of predominantly slow-fiber type. The baseline tension developed in soleus muscles during saponin exposure was similar to that in EDL muscles (data not shown). Surprisingly, the tetanic force recovered to $\sim 80 \%$ at 10 minutes after the 5-minute saponin exposure regardless of dysferlin genotype (Figure 4(e) and Table 2). We observed only a small but significant increase in the tetanic force at 20 minutes compared to that at 10 minutes, and there was no further force recovery in the following 40 minutes (Figure 4(e) and Table 2). To further confirm that the tetanic force was indeed rapidly recovering within the first 10 

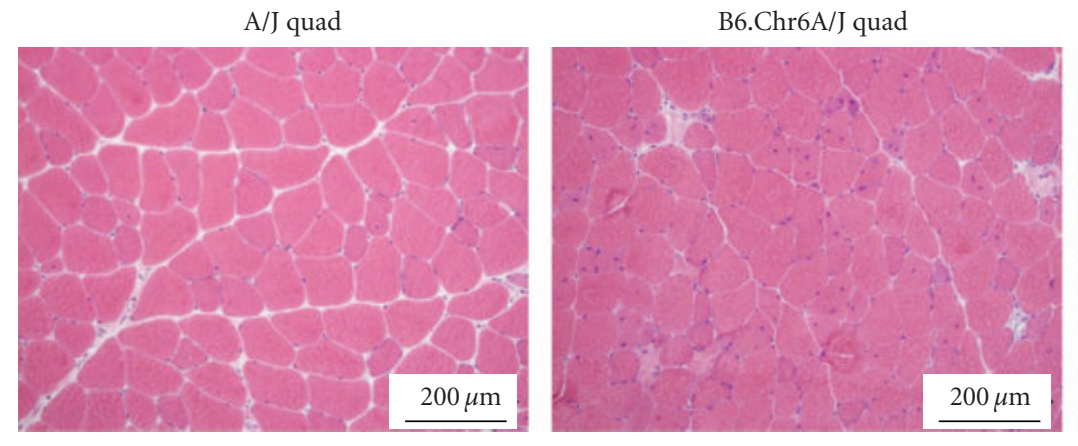

(a)

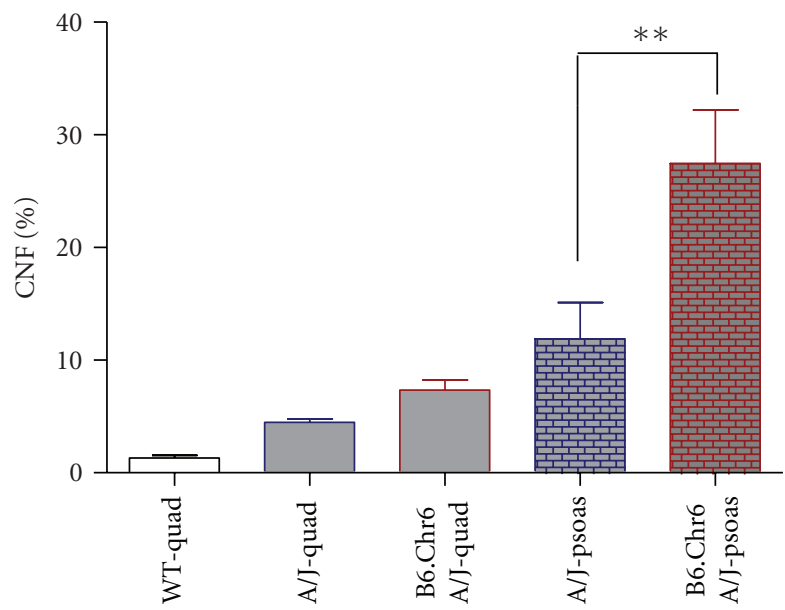

(b)
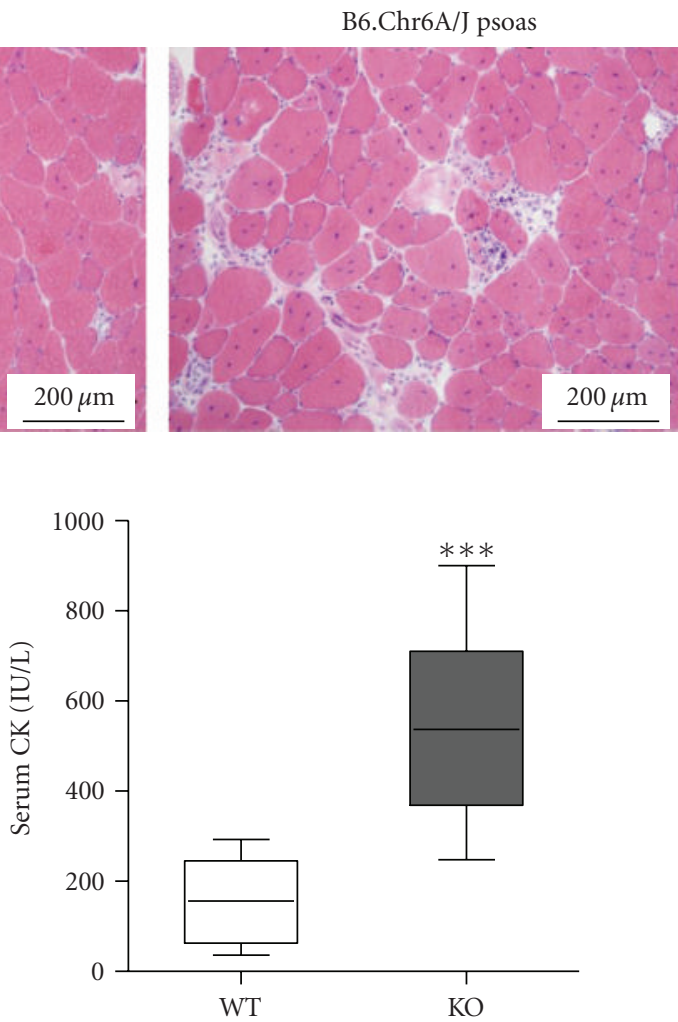

(c)

FIGURE 2: Characterization of C57BL/6J-Chr6 ${ }^{\mathrm{A} / \mathrm{J}} / \mathrm{NaJ}$ mice. (a) H\&E-stained quadriceps (or iliopsoas) muscle sections of A/J, B6.Chr6A/J mice. Scale bar: $200 \mu \mathrm{m}$. (b) Central nucleated muscle fiber percentage (CNF) from the quadriceps or iliopsoas muscles of WT, A/J, and B6.Chr6A/J mice at 16 weeks of age. (c) Serum creatine kinase (CK) levels from WT $(N=6)$ and B6.Chr6A/J $(\mathrm{KO})(N=10)$ mice at 16 weeks of age. ${ }^{* *}$ indicates $P<0.05$, and ${ }^{* * *}$ indicates $P<0.001$.

TABLE 1: Tetanic forces $\left(\mathrm{kN} / \mathrm{m}^{2}\right)$ of WT and dysferlin-null EDL muscles at room temperature before and after saponin exposure.

\begin{tabular}{lccccccc}
\hline & Initial & $10 \mathrm{~min}$ & $20 \mathrm{~min}$ & $30 \mathrm{~min}$ & $40 \min$ & $50 \mathrm{~min}$ & $60 \mathrm{~min}$ \\
\hline \multirow{2}{*}{ WT, $N=5$} & $273.6 \pm 4.9$ & $41.9 \pm 6.1$ & $75.7 \pm 10.2$ & $101.7 \pm 11.5$ & $114.5 \pm 11.8$ & $117.1 \pm 11.8$ & $117.0 \pm 11.1$ \\
& & & $(\mathrm{a})=0.002$ & $P=0.0007$ & $P=0.18$ & $P=0.18$ & $P=0.92$ \\
KO, $N=5$ & $251.3 \pm 13.5$ & $47.5 \pm 15.0$ & $77.4 \pm 14.8$ & $97.1 \pm 18.3$ & $102.1 \pm 19.0$ & $102.2 \pm 18.7$ & $102.4 \pm 18.6$ \\
(b) $P$ & & & $P=0.016$ & $P=0.042$ & $P=0.048$ & $P=0.81$ & $P=0.83$ \\
& 0.09 & 0.74 & 0.93 & 0.84 & 0.59 & 0.52 & 0.52 \\
\hline
\end{tabular}

Note: (a) the $P$ values under the force data are the paired $t$-test of the forces at the specific time point compared to that measured at the prior time point (e.g., WT force at $20 \mathrm{~min}$ compared to that at $10 \mathrm{~min}$ ); (b) the $P$ values in the last row are the unpaired $t$-test of forces between WT and dysferlin-null groups at each time point.

TABLE 2: Tetanic forces $\left(\mathrm{kN} / \mathrm{m}^{2}\right)$ of WT and dysferlin-null soleus muscles at room temperature before and after saponin exposure.

\begin{tabular}{lccccccc}
\hline & Initial & $10 \mathrm{~min}$ & $20 \mathrm{~min}$ & $30 \mathrm{~min}$ & $40 \min$ & $50 \mathrm{~min}$ & $60 \mathrm{~min}$ \\
\hline \multirow{2}{*}{ WT, $N=5$} & $166.5 \pm 6.7$ & $130.8 \pm 4.1$ & $139.8 \pm 3.6$ & $137.7 \pm 3.1$ & $135.0 \pm 2.8$ & $133.4 \pm 2.9$ & $132.2 \pm 3.9$ \\
& & & $P=0.002$ & $P=0.32$ & $P=0.04$ & $P=0.75$ & $P=0.94$ \\
KO, $N=7$ & $171.0 \pm 11.9$ & $138.3 \pm 8.4$ & $145.6 \pm 8.3$ & $142.6 \pm 7.8$ & $139.7 \pm 7.6$ & $138.5 \pm 7.6$ & $136.9 \pm 7.8$ \\
${ }^{(b)} P$ & & & $P=0.003$ & $P=0.15$ & $P=0.13$ & $P=0.34$ & $P=0.42$ \\
& 0.77 & 0.49 & 0.59 & 0.62 & 0.63 & 0.60 & 0.64 \\
\hline
\end{tabular}

Note: (a) the $P$ values under the force data are the paired $t$-test of the forces at the specific time point compared to that measured at the prior time point (e.g., WT force at 20 min compared to that at $10 \mathrm{~min}$ ); (b) the $P$ values in the last row are the unpaired $t$-test of forces between WT and dysferlin-null groups at each time point. 
WT
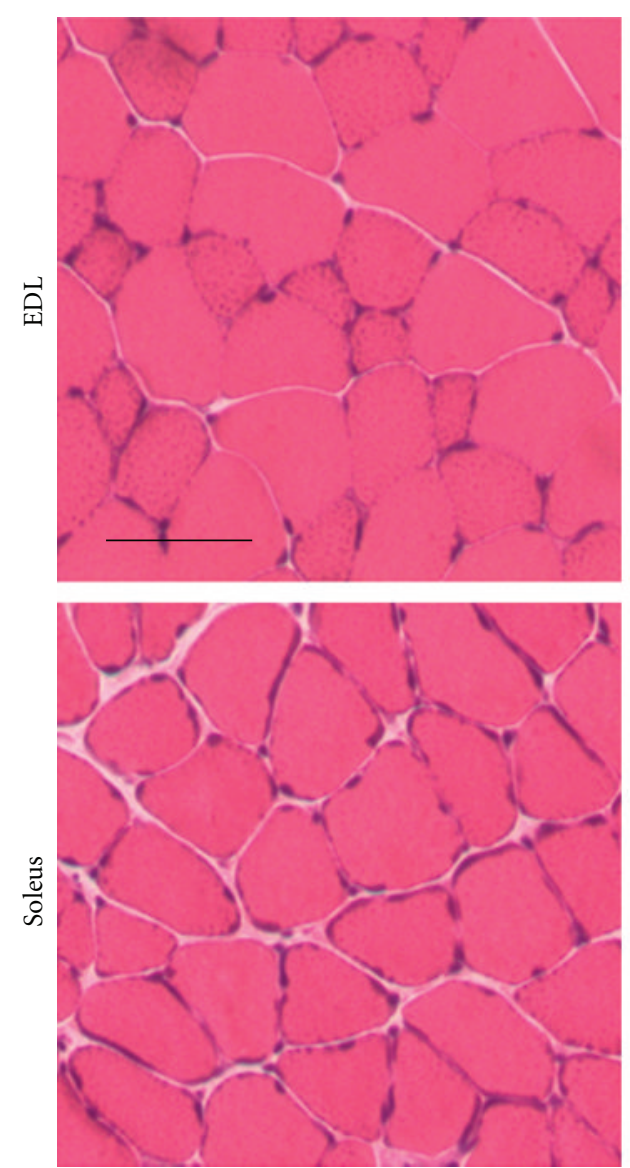

B6.Chr6A/J
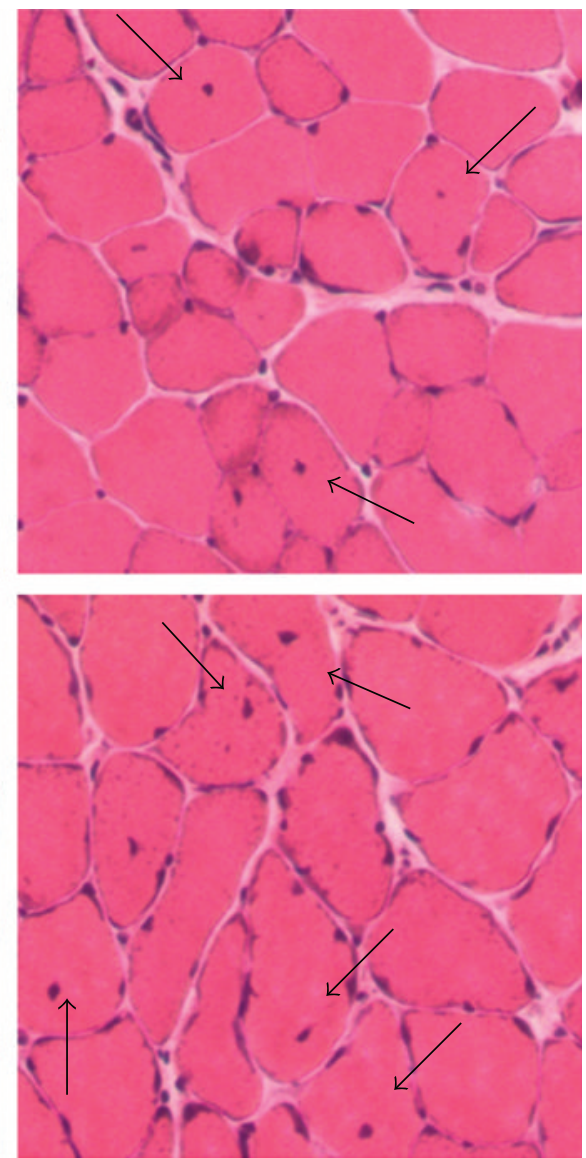

FIGURE 3: Histology examination of EDL and soleus muscles from C57BL/6J-Chr6 ${ }^{\mathrm{A} / \mathrm{J}} / \mathrm{NaJ}$ mice. H\&E-stained EDL (top panel) and soleus (bottom panel) muscle sections of C57BL/6J (WT) and C57BL/6J-Chr6 ${ }^{\mathrm{A} / \mathrm{J}} / \mathrm{NaJ}$ mice. Scale bar: $100 \mu \mathrm{m}$.

minutes, we measured tetanic force at 5 minutes following saponin washout in four soleus muscles (two WT and two mutants). As shown in Figure 4(e), the soleus muscles developed $69 \%$ of maximum force at 5 minutes. By fitting the data with a one-phase association equation, we estimated the maximum recovery percentage to be $45.9 \pm 4.4 \%$ in EDL and $84.4 \pm 1.2 \%$, and the rate of recovery to be $0.057 \pm 0.025$ $\left(\mathrm{min}^{-1}\right)$ in EDL and $0.268 \pm 0.097\left(\mathrm{~min}^{-1}\right)$ in soleus. This data suggests that the soleus muscles recovered much faster than the EDL muscles after saponin washout.

\section{Discussion}

The plasma membrane defines the boundary of every single living cell, and its integrity is essential for life. However, the plasma membrane may be challenged by mechanical stress during normal physiological activities or PFPs produced by the organism itself and invading pathogens. For example, pore formation by perforin is involved in counteracting infection by microorganisms [19], while pore formation by the Bcl2 family member Bax triggers apoptosis [39]. Furthermore, it has been shown that the causative agents of Alzheimer's or Parkinson's disease are proteins capable of adopting pore-forming configurations [23, 40], and poreforming amyloid deposits are also found in muscle diseases
[25]. Pore formation through complexation with cholesterol and subsequent oligomerization leads to permeabilization of ions and small molecules such as ATP and, in the case of CDCs, leakage of proteins [26]. Repairing the membrane damage induced by PFPs is thus a critical step for the inflicted cell to survive.

Mammalian cells have been shown to be capable of repairing breaches in their plasma membrane. Dysferlin and MG53 were two previously identified proteins that play critical roles in repairing laser irradiation- and microneedleinduced membrane damage in striated muscles $[5,7,12$, 41]. Our present study demonstrated that skeletal muscle is also capable of repairing (at least partially) saponininduced membrane damage. In the case of EDL muscles, the maximum recovery of tetanic force was around $44.6 \%$ after a 5-min exposure to $50 \mu \mathrm{g} / \mathrm{mL}$ saponin. The force deficit indicates "permanent" damage had occurred by saponin exposure. It is likely that the muscle fibers in the outer layers were more severely damaged because they were more accessible to saponin. However, there were no differences in the maximum recovery levels in the WT and dysferlindeficient groups, suggesting that the levels of "permanent" damage in the two groups were the same. Thus, the same recovery rate in both WT and dysferlin-deficient EDL 


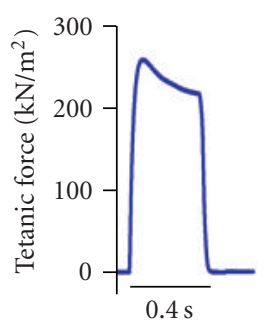

(a)

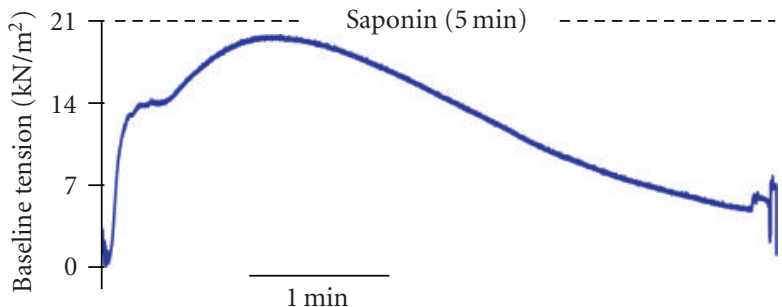

(b)

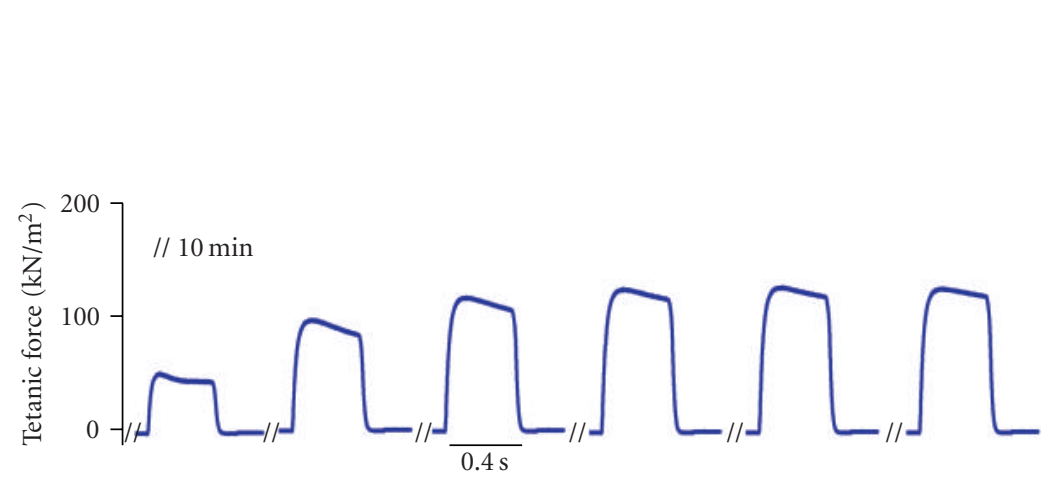

(c)

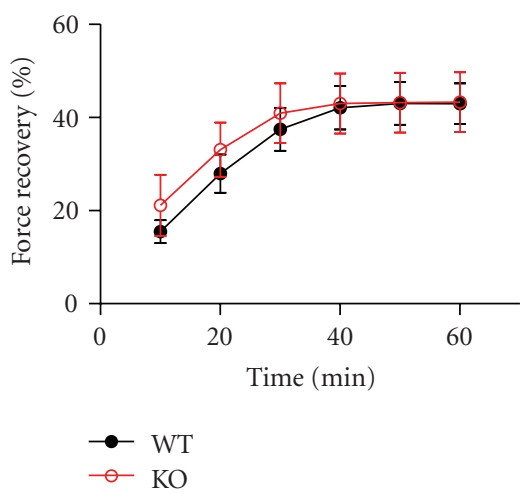

(d)

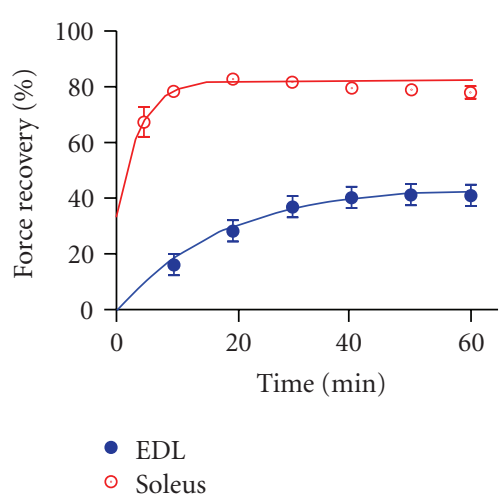

(e)

FIGURE 4: Tetanic force recovery in WT and C57BL/6J-Chr6 ${ }^{\mathrm{A} / \mathrm{J}} / \mathrm{NaJ}$ EDL and soleus muscles following saponin exposure. (a) Representative tetanic force measurement in a WT EDL muscle before saponin exposure. (b) Representative tension trace during saponin $(50 \mu \mathrm{g} / \mathrm{mL})$ exposure at room temperature (RT). (c) Representative tetanic force measurements within one hour after saponin washout at RT. Double slash: $10 \mathrm{~min}$. (d) Quantitative analysis of the muscle force recovery in EDL muscles of WT and dysferlin-deficient mice at RT. (e) Tetanic force recovery in soleus muscles and EDL muscles $(N=10$ and 13 for EDL and soleus, resp.) after saponin (50 $\mu \mathrm{g} / \mathrm{mL})$ exposure at room temperature. Note: we pooled the WT and mutant muscle data in panel (e) since there was no significant difference between the two groups (see Tables 1-2).

muscles suggests that dysferlin may not be involved in this process. We do not think this data is against previous reports showing dysferlin is required to repair laser-induced injury. Repairing laser-induced membrane damage is dysferlindependent, and this has been independently confirmed by several groups $[12,38,42,43]$. Interestingly, the laserinduced membrane damage is around $5 \mu \mathrm{m}$ in diameter at only a single spot of the muscle fiber $[5,7,22]$. However, the membrane pores induced by pore-forming reagents are up to $50 \mathrm{~nm}$ in diameter, but spread along the entire surface of the cells in contact with the reagents. Repairing these two different types of membrane injuries may use different mechanisms [26]. Consistent with this notion, repairing laser-induced membrane damage takes seconds (e.g., within 1-2 minutes) $[5,7,9]$, but repairing the pores induced by streptolysin $\mathrm{O}$ and perforin takes minutes ( $<1$ hour) [13, 29 ], and it takes even longer ( $>6$ hours) to recover from pore formation induced by toxins such as Staphylococcal $\alpha$-toxin $[31,44]$. In our experiments, it took up to $30-$ 40 minutes for the EDL muscles to recover from saponininduced membrane damage. We, thus, interpret this data to mean that skeletal muscle cells may use different mechanism to repair membrane damage induced by PFPs as compared to laser irradiation. The detailed mechanisms leading to 
recovery of membrane integrity following pore formation remain to be explored. But it has been shown that this process involves a $\mathrm{Ca}^{2+}$-dependent and dynamin-mediated endocyotosis coupled with exocytosis which rapidly removes the PFPs from the cell membrane $[13,31,32,45]$.

Another interesting observation in our study is that the slow soleus muscle recovers significantly greater force compared to fast EDL muscle suggesting that the slow muscle has a more efficient way to recover from saponin-induced membrane injury. Compared to the fast EDL muscle, the slow soleus muscle has many different properties in addition to the difference in their contraction velocity. For example, it was shown that the soleus muscle from a glycosylationdeficient muscular dystrophy mouse model-Large $e^{\text {myd }}$ exhibits no greater force deficit compared with WT soleus muscle [46] although the EDL muscle from the same mouse model is highly susceptible to contraction-induced injury [35]. This difference was attributed to the increased expression of sarcolemmal $\beta 1$-integrin in the soleus muscle than the EDL muscle [46]. The difference in the force recovery rate upon saponin-induced membrane injury between soleus and EDL muscles remains unclear and warrants further investigation.

In summary, we demonstrated that the skeletal muscle possesses the ability to repair membrane damages induced by pore-forming reagents such as saponin. This repair process takes 30-40 minutes for EDL muscles and up to 20 minutes for soleus muscles. Finally, dysferlin deficiency has little effect on the recovery.

\section{Conflict of Interests}

The authors declare that no conflict of interests exists.

\section{Acknowledgments}

The authors thank Guogen $\mathrm{Wu}$ for technical assistance. Research support was provided by the American Heart Association Scientist Development Award 10SDG4140138 (to R. Han), Muscular Dystrophy Association research Grant MDA171667 (to R. Han), American Heart Association postdoctoral fellowship 11POST5260038 (to Y. Ait-Mou), National Institute of Health Grants HL62426 and HL75494 (to P. de Tombe). Support for the Department of Cell and Molecular Physiology Multiphoton Imaging Facility was provided by the McCormick Foundation. The funders had no role in study design, data collection and analysis, decision to publish, or preparation of the manuscript.

\section{References}

[1] R. Bashir, S. Britton, T. Strachan et al., "A gene related to caenorhabditis elegans spermatogenesis factor fer- 1 is mutated in limb-girdle muscular dystrophy type 2B," Nature Genetics, vol. 20, no. 1, pp. 37-42, 1998.

[2] J. Liu, M. Aoki, I. Illa et al., "Dysferlin, a novel skeletal muscle gene, is mutated in Miyoshi myopathy and limb girdle muscular dystrophy," Nature Genetics, vol. 20, no. 1, pp. 31-36, 1998.
[3] I. Illa, C. Serrano-Munuera, E. Gallardo et al., "Distal anterior compartment myopathy: a dysferlin mutation causing a new muscular dystrophy phenotype," Annals of Neurology, vol. 49, no. 1, pp. 130-134, 2001.

[4] S. Kuru, F. Yasuma, T. Wakayama et al., "A patient with limb girdle muscular dystrophy type 2B (LGMD2B) manifesting cardiomyopathy," Clinical Neurology, vol. 44, no. 6, pp. 375378, 2004.

[5] R. Han, D. Bansal, K. Miyake et al., "Dysferlin-mediated membrane repair protects the heart from stress-induced left ventricular injury," Journal of Clinical Investigation, vol. 117, no. 7, pp. 1805-1813, 2007.

[6] L. V. B. Anderson, K. Davison, J. A. Moss et al., "Dysferlin is a plasma membrane protein and is expressed early in human development," Human Molecular Genetics, vol. 8, no. 5, pp. 855-861, 1999.

[7] D. Bansal, K. Miyake, S. S. Vogel et al., "Defective membrane repair in dysferlin-deficient muscular dystrophy," Nature, vol. 423, no. 6936, pp. 168-172, 2003.

[8] D. Bansal and K. P. Campbell, "Dysferlin and the plasma membrane repair in muscular dystrophy," Trends in Cell Biology, vol. 14, no. 4, pp. 206-213, 2004.

[9] R. Han and K. P. Campbell, "Dysferlin and muscle membrane repair," Current Opinion in Cell Biology, vol. 19, no. 4, pp. 409416, 2007.

[10] W. P. Thorpe, M. Toner, R. M. Ezzell, R. G. Tompkins, and M. L. Yarmush, "Dynamics of photoinduced cell plasma membrane injury," Biophysical Journal, vol. 68, no. 5, pp. 2198-2206, 1995.

[11] A. W. Girotti and M. R. Deziel, "Photodynamic action of protoporphyrin on resealed erythrocyte membranes: mechanisms of release of trapped markers," Advances in Experimental Medicine and Biology, vol. 160, pp. 213-225, 1983.

[12] C. Cai, H. Masumiya, N. Weisleder et al., "MG53 nucleates assembly of cell membrane repair machinery," Nature Cell Biology, vol. 11, no. 1, pp. 56-64, 2009.

[13] D. Keefe, L. Shi, S. Feske et al., "Perforin triggers a plasma membrane-repair response that facilitates CTL induction of apoptosis," Immunity, vol. 23, no. 3, pp. 249-262, 2005.

[14] M. J. Spencer, C. M. Walsh, K. A. Dorshkind, E. M. Rodriguez, and J. G. Tidball, "Myonuclear apoptosis in dystrophic mdx muscle occurs by perforin-mediated cytotoxicity," Journal of Clinical Investigation, vol. 99, no. 11, pp. 2745-2751, 1997.

[15] T. Sugihara, N. Okiyama, M. Suzuki et al., "Definitive engagement of cytotoxic CD8 T cells in C protein-induced myositis, a murine model of polymyositis," Arthritis and Rheumatism, vol. 62, no. 10, pp. 3088-3092, 2010.

[16] L. E. Ramm, M. B. Whitlow, and M. M. Mayer, "Transmembrane channel formation by complement: functional analysis of the number of $\mathrm{C} 5 \mathrm{~b} 6, \mathrm{C} 7, \mathrm{C} 8$, and $\mathrm{C} 9$ molecules required for a single channel," Proceedings of the National Academy of Sciences of the United States of America, vol. 79, no. 15, pp. 4751-4755, 1982.

[17] L. E. Ramm, M. B. Whitlow, and M. M. Mayer, "Size of the transmembrane channels produced by complement proteins C5b-8," Journal of Immunology, vol. 129, no. 3, pp. 1143-1146, 1982.

[18] L. E. Ramm and M. M. Mayer, "Life-span and size of the transmembrane channel formed by large doses of complement," Journal of Immunology, vol. 124, no. 5, pp. 2281-2287, 1980.

[19] M. E. Pipkin and J. Lieberman, "Delivering the kiss of death: progress on understanding how perforin works," Current Opinion in Immunology, vol. 19, no. 3, pp. 301-308, 2007. 
[20] C. J. Rosado, A. M. Buckle, R. H. P. Law et al., "A common fold mediates vertebrate defense and bacterial attack," Science, vol. 317, no. 5844, pp. 1548-1551, 2007.

[21] M. A. Hadders, D. X. Beringer, and P. Gros, "Structure of $\mathrm{C} 8 \alpha$-MACPF reveals mechanism of membrane attack in complement immune defense," Science, vol. 317, no. 5844, pp. 1552-1554, 2007.

[22] R. Han, E. M. Frett, J. R. Levy et al., "Genetic ablation of complement C3 attenuates muscle pathology in dysferlindeficient mice," Journal of Clinical Investigation, vol. 120, no. 12, pp. 4366-4374, 2010.

[23] H. A. Lashuel and P. T. Lansbury, "Are amyloid diseases caused by protein aggregates that mimic bacterial pore-forming toxins?" Quarterly Reviews of Biophysics, vol. 39, no. 2, pp. 167-201, 2006.

[24] Y. Yoshiike, R. Kayed, S. C. Milton, A. Takashima, and C. G. Glabe, "Pore-forming proteins share structural and functional homology with amyloid oligomers," NeuroMolecular Medicine, vol. 9, no. 3, pp. 270-275, 2007.

[25] S. Spuler, M. Carl, J. Zabojszcza et al., "Dysferlin-deficient muscular dystrophy features amyloidosis," Annals of Neurology, vol. 63, no. 3, pp. 323-328, 2008.

[26] M. Bischofberger, M. R. Gonzalez, and F. G. van der Goot, "Membrane injury by pore-forming proteins," Current Opinion in Cell Biology, vol. 21, no. 4, pp. 589-595, 2009.

[27] J. A. Johnson, M. O. Gray, J. S. Karliner, C. H. Chen, and D. Mochly-Rosen, "An improved permeabilization protocol for the introduction of peptides into cardiac myocytes: application to protein kinase C research," Circulation Research, vol. 79, no. 6, pp. 1086-1099, 1996.

[28] S. Shany, A. W. Bernheimer, P. S. Grushoff, and K. S. Kim, "Evidence for membrane cholesterol as the common binding site for cereolysin, streptolysin O and saponin," Molecular and Cellular Biochemistry, vol. 3, no. 3, pp. 179-186, 1974.

[29] I. Walev, S. C. Bhakdi, F. Hofmann et al., "Delivery of proteins into living cells by reversible membrane permeabilization with streptolysin-O," Proceedings of the National Academy of Sciences of the United States of America, vol. 98, no. 6, pp. 31853190, 2001.

[30] O. Moskovich and Z. Fishelson, "Live cell imaging of outward and inward vesiculation induced by the complement C5b-9 complex," Journal of Biological Chemistry, vol. 282, no. 41, pp. 29977-29986, 2007.

[31] M. Husmann, E. Beckmann, K. Boller et al., "Elimination of a bacterial pore-forming toxin by sequential endocytosis and exocytosis," FEBS Letters, vol. 583, no. 2, pp. 337-344, 2009.

[32] V. Idone, C. Tam, J. W. Goss, D. Toomre, M. Pypaert, and N. W. Andrews, "Repair of injured plasma membrane by rapid $\mathrm{Ca}^{2+}$ dependent endocytosis," Journal of Cell Biology, vol. 180, no. 5, pp. 905-914, 2008.

[33] R. Coral-Vazquez, R. D. Cohn, S. A. Moore et al., "Disruption of the sarcoglycan-sarcospan complex in vascular smooth muscle: a novel mechanism for cardiomyopathy and muscular dystrophy," Cell, vol. 98, no. 4, pp. 465-474, 1999.

[34] M. Durbeej, R. D. Conn, R. F. Hrstka et al., "Disruption of the $\beta$-sarcoglycan gene reveals pathogenetic complexity of limbgirdle muscular dystrophy type 2E," Molecular Cell, vol. 5, no. 1, pp. 141-151, 2000.

[35] R. Han, M. Kanagawa, T. Yoshida-Moriguchi et al., "Basal lamina strengthens cell membrane integrity via the laminin G domain-binding motif of $\alpha$-dystroglycan," Proceedings of the National Academy of Sciences of the United States of America, vol. 106, no. 31, pp. 12573-12579, 2009.
[36] J. H. Nadeau, J. B. Singer, A. Matin, and E. S. Lander, "Analysing complex genetic traits with chromosome substitution strains," Nature Genetics, vol. 24, no. 3, pp. 221-225, 2000.

[37] M. Ho, C. M. Post, L. R. Donahue et al., "Disruption of muscle membrane and phenotype divergence in two novel mouse models of dysferlin deficiency," Human Molecular Genetics, vol. 13, no. 18, pp. 1999-2010, 2004.

[38] W. Lostal, M. Bartoli, N. Bourg et al., "Efficient recovery of dysferlin deficiency by dual adeno-associated vector-mediated gene transfer," Human Molecular Genetics, vol. 19, no. 10, Article ID ddq065, pp. 1897-1907, 2010.

[39] G. Kroemer, L. Galluzzi, and C. Brenner, "Mitochondrial membrane permeabilization in cell death," Physiological Reviews, vol. 87, no. 1, pp. 99-163, 2007.

[40] M. F. M. Engel, L. Khemtémourian, C. C. Kleijer et al., "Membrane damage by human islet amyloid polypeptide through fibril growth at the membrane," Proceedings of the National Academy of Sciences of the United States of America, vol. 105, no. 16, pp. 6033-6038, 2008.

[41] X. Wang, W. Xie, Y. Zhang et al., "Cardioprotection of ischemia/reperfusion injury by cholesterol-dependent MG53mediated membrane repair," Circulation Research, vol. 107, no. 1, pp. 76-83, 2010.

[42] J. Díaz-Manera, T. Touvier, A. Dellavalle et al., "Partial dysferlin reconstitution by adult murine mesoangioblasts is sufficient for full functional recovery in a murine model of dysferlinopathy," Cell Death and Disease, vol. 1, no. 8, article e61, 2010.

[43] M. Krahn, N. Wein, M. Bartoli et al., "A naturally occurring human minidysferlin protein repairs sarcolemmal lesions in a mouse model of dysferlinopathy," Science Translational Medicine, vol. 2, no. 50, Article ID 50ra69, 2010.

[44] M. Husmann, K. Dersch, W. Bobkiewicz, E. Beckmann, G. Veerachato, and S. Bhakdi, "Differential role of p38 mitogen activated protein kinase for cellular recovery from attack by pore-forming S. aureus $\alpha$-toxin or streptolysin O," Biochemical and Biophysical Research Communications, vol. 344, no. 4, pp. 1128-1134, 2006.

[45] L. E. Ramm, M. B. Whitlow, and C. L. Koski, "Elimination of complement channels from the plasma membranes of U937, a nucleated mammalian cell line: temperature dependence of the elimination rate," Journal of Immunology, vol. 131, no. 3, pp. 1411-1415, 1983.

[46] J. D. Gumerson, Z. T. Kabaeva, C. S. Davis, J. A. Faulkner, and D. E. Michele, "Soleus muscle in glycosylation-deficient muscular dystrophy is protected from contraction-induced injury," American Journal of Physiology, vol. 299, no. 6, pp. C1430-C1440, 2010. 

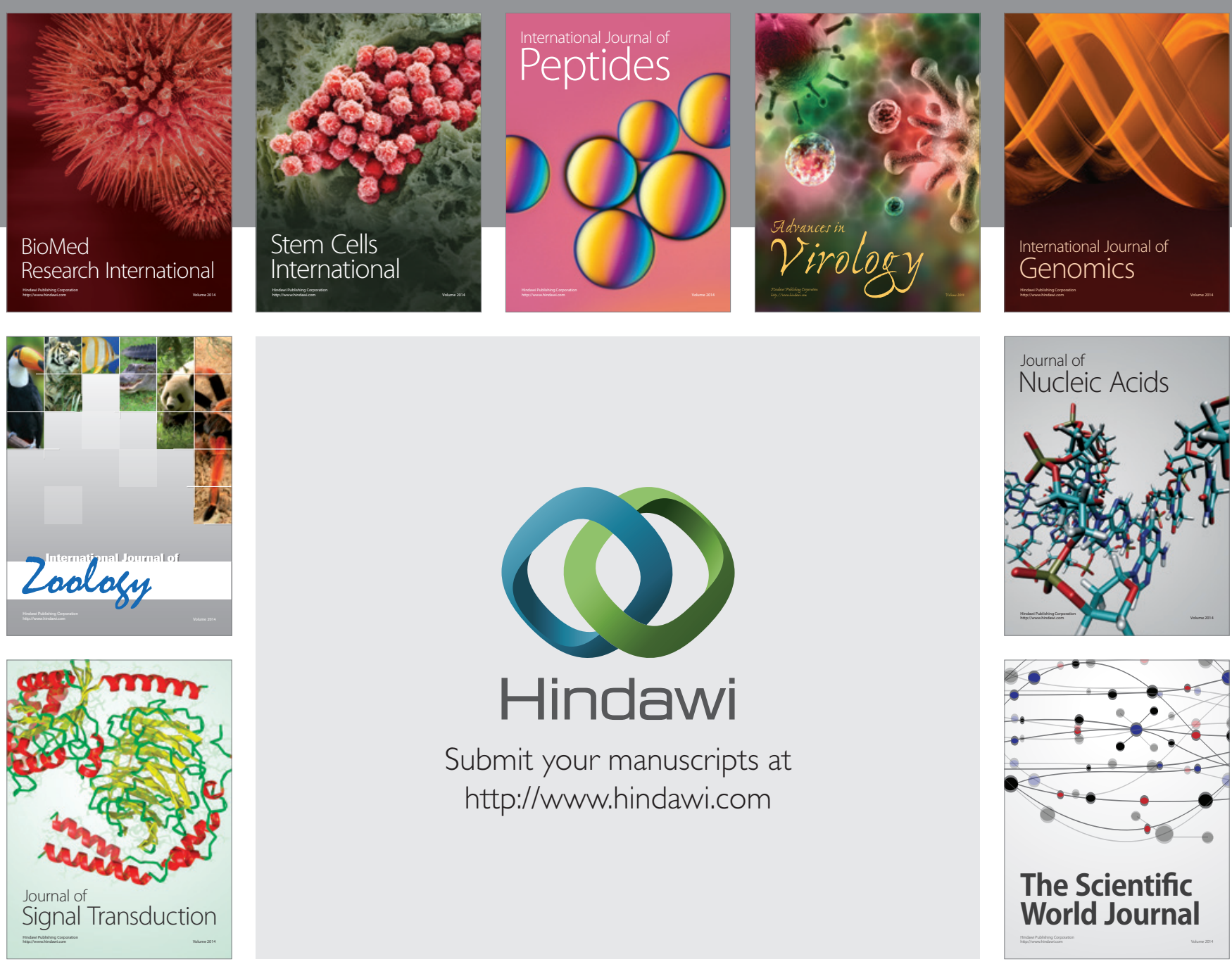

Submit your manuscripts at

http://www.hindawi.com
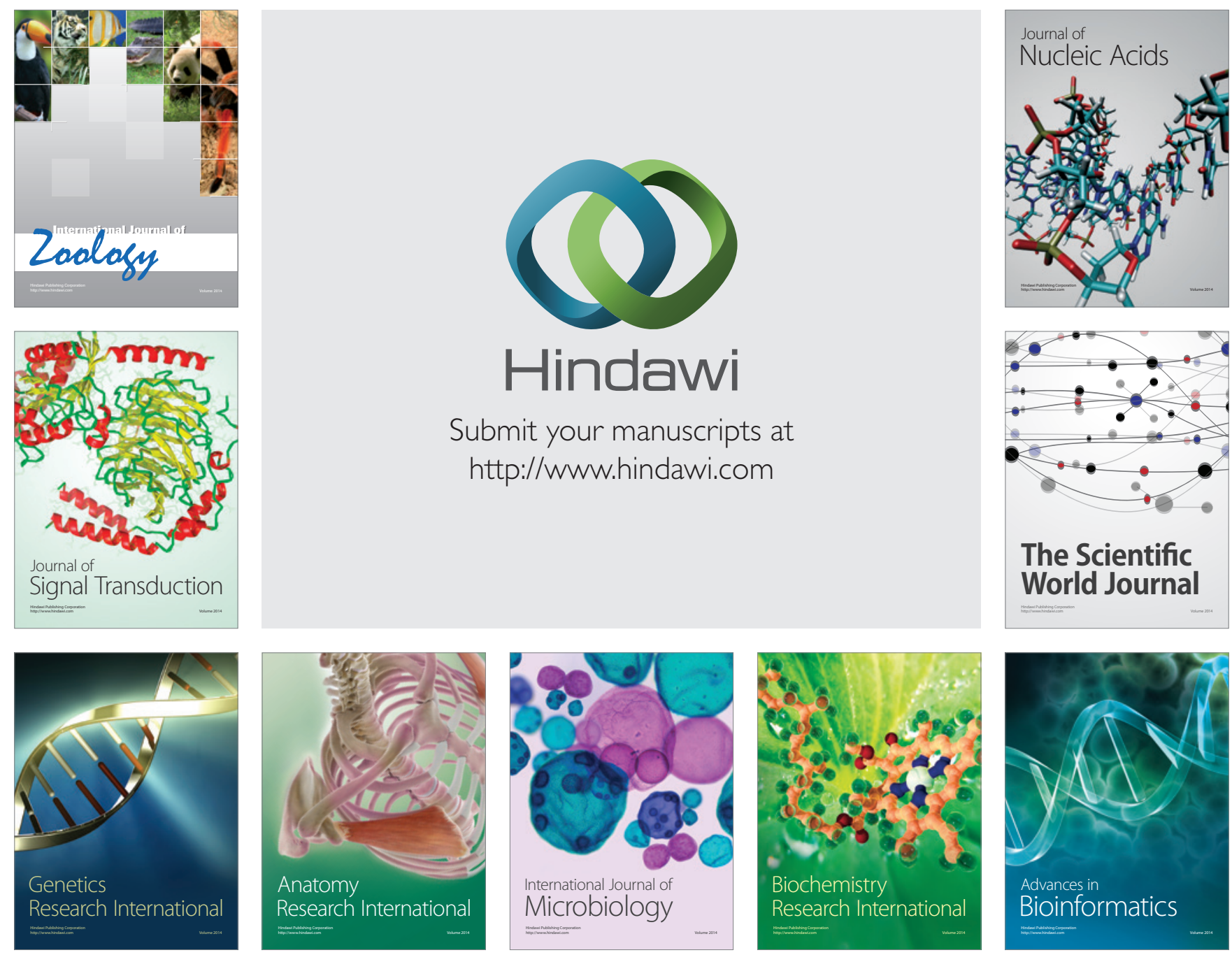

The Scientific World Journal
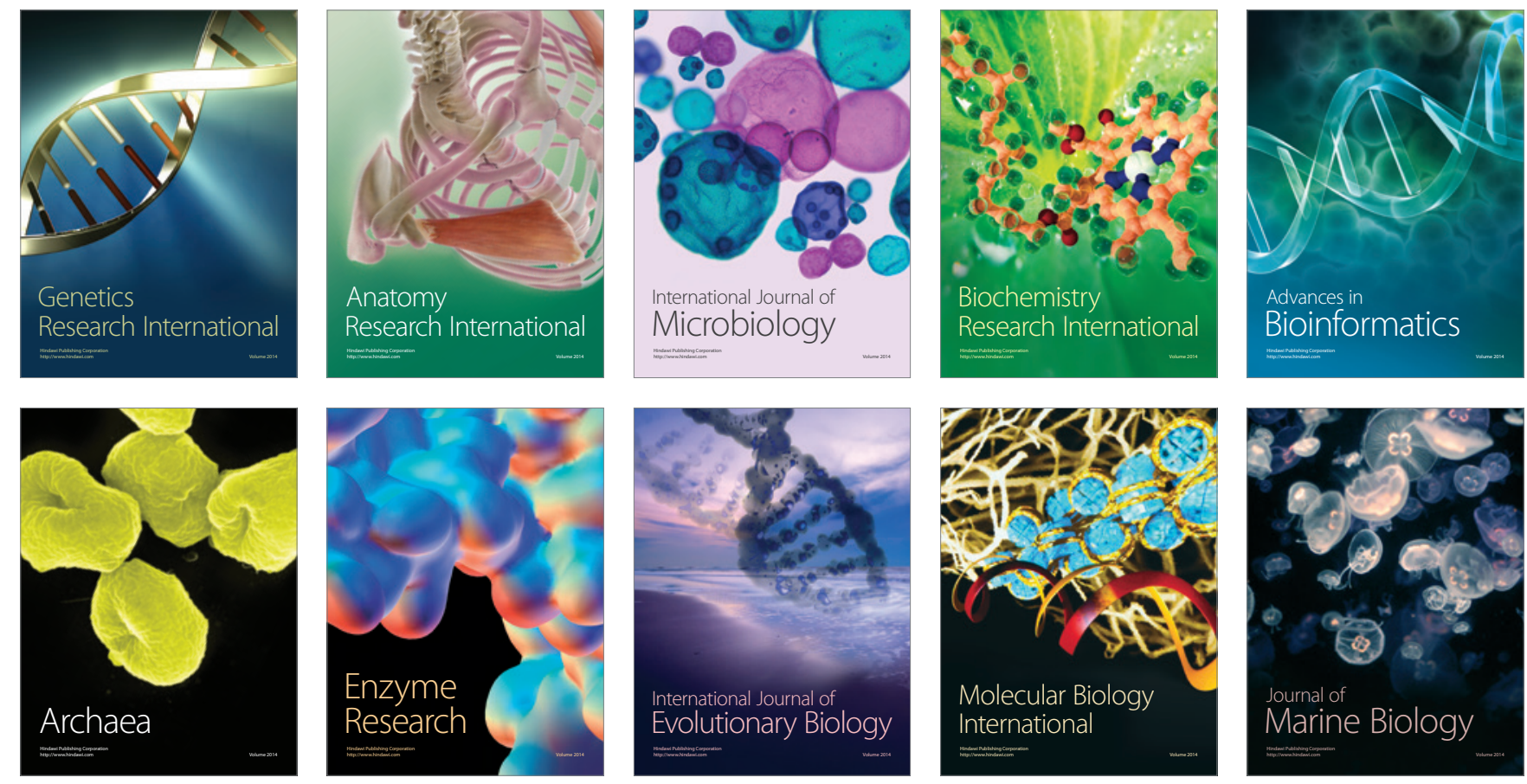